\title{
CLEFT LIP AND PALATE NUTRITIONAL ASSESSMENT AND FEEDING CHALLENGES
}

\author{
Haitham Attia*
}

\begin{abstract}
Purpose: The present study aimed to highpoint the feeding challenges of infants with cleft lip and/or palate (CLP) that caregivers and parents came across and analyse the different interventions they perform in the preoperative period. Design and methods: Parents of 100 infants with CLP were asked to complete the questionnaire. The feeding preparations and challenges with alternatives to overcome these difficulties were evaluated. Results: Forty- six percent of the parents that their infants were diagnosed prenatally received an education for feeding. Breastfeeding was not successful $77.9 \%$. Infants affected with isolated cleft palate and cleft lip and palate reported difficulties and more complication than isolated cleft lip patients. Parents stated that $56 \%$ of the infants with cleft had stayed in the intensive care units following birth. On the other hand, $40 \%$ of the infants were fed by nasogastric or orogastric tube primely. Thirty-five percent of cleft palate patients used palatal obturators. Conclusions: The study highlights the feeding challenges that had been faced by parents, caregivers and health care providers.
\end{abstract}

KEYWORDS: cleft lip, cleft palate, feeding, nutrition, questionnaire, intensive care unit (ICU).

\section{INTRODUCTION}

Cleft lip and palate (CLP) are by far the most occurring craniofacial deformities, may be syndromic or non-syndromic, or associated with various systems affection as cardiovascular, pulmonary, and auditory. Impairment of speech and dental anomalies are among the most common problems accompanying (CLP) ${ }^{1,2}$. The incidence of occurrence is one in every 700 live births worldwide (World Health Organization [WHO], 2001).
After birth, feeding comes in first with a dilemma of sucking and swallowing, due to lack of intraoral negative pressure and nipple seal. The caretaker and infant will be subjected to stressful feeding due to decrease volume intake by infant that leads to prolonged feeding time ${ }^{3,4}$. Improper sucking predisposes to devasting effect on growth, choking and dehydration ${ }^{5}$. Doubts and questions are ghosts hunting patents having infant suffering from (CLP); one of these questions is the feeding, how they can manage? Shall they ask for professional take-care

* Associate Professor Oral and Maxillofacial Surgery, Faculty of Dentistry, King Abdulaziz University, Faculty of Dentistry, Suez Canal University 
giver help and support? ${ }^{6}$.There is dearth of data regarding studies focusing on feeding problems and approaches to be developed to compensate for such difficulty with (CLP) infants. Feeding difficulty or feeding skills as described by different authors, occurs in a range of one third to a maximum of two thirds of the infants ${ }^{7,8}$.

Breast feeding and spoon feeding are ways to be used by parents and care-giver aiming to provide infants with nutrition for their development. Spoon feeding is the first choice for parents with CLP ${ }^{9}$.

The present study aimed to evaluate the care practices associated with infants with CLP in multicentre, highlight the feeding challenges of these infants that caregivers encounter and analysis the alternative feeding interventions they perform in the preoperative period based on their experiences. A secondary aim was to compare the rate of alternative feeding interventions and ICU admissions among different cleft types.

\section{PATIENTS AND METHODS}

Parents of 100 infants born in Egypt and Saudi Arabia suffering from CLP who had surgical correction between July $1^{\text {st }}, 2017$ and August $15^{\text {th }}$, 2018, were included in the study. Cleft lip surgeries were performed approximately at 45 days of age, and cleft palate closure around 9 months of age. A written informed consent was signed by each parent. The study was approved by ethic committee in each centre. Syndromic CLP cases were not included in this study; infants with CLP only. Some parents might have doubts in their responses, therefore, assessment of such doubts had to be done before through completing questionnaire by 10 parents not contributing in this study.

The questionnaire design was based on feeding difficulties and challenges that had been faced by caregivers and parents. Every case represents a new challenge to the managing team. These challenges have been translated into the questionnaire, based on clinical experience. The questionnaire was completed by the parents during routine followup. All patient had been seen post-operatively after one week, 4 weeks, 3 months, 6 months and one year. The questionnaire contains ten statements with combined multiple choices and open-ended ones, both helped in assessment of prenatal feeding provision, processes, challenges and modification to overcome such difficulties. All infant's data regarding gender, cleft side, type, feeding difficulties and ways to improve feeding were statistically analysed.

Data for this study were analysed using IBM SPSS Statistics for Windows version 22.0 (IBM Corporation, Armonk, New York, USA). The responses to the analysed using Mann-Whitney $\mathrm{U}$ test and chi-squared test for numerical and categorical variables, respectively. Categorical variables were expressed as frequencies and percentages. Quantitative data were described using median, minimum, And maximum values. The rate of alternative feeding interventions such as placement of nasogastric or orogastric tubes and the success rates in breastfeeding among different cleft types were compared. ICU admission rates and the average length of stay in the ICUs were compared between infants' parents who had received feeding education prenatally and the ones who had not received education. Additionally, after the exclusion of isolated labial clefts and small soft palatal clefts, analysis on the infants who had not suffered from any feeding difficulties was performed to detect the role of the obturators. Patients who had used obturators and the ones who had not used them were compared. P-values b0.05 were considered statistically significant.

\section{RESULTS}

This study was composed of 100 parents whose infants suffered from cleft lip and or cleft palate deformity and underwent corrective surgery in 
multicentre. Of the 100 cleft patients $56 \%$ were males and $44 \%$ were females, $15 \%$ had isolated cleft lip, $32 \%$ had isolated cleft palate and 53\% had cleft lip and palate. Table 1 presented the demographic data of all infants.

\section{Prenatal and postnatal period}

Among the 100 infants who were under prenatal screening with ultrasonography, 37 parents confirmed that their infants were diagnosed with cleft deformity. Once they were diagnosed with such condition 34 out of 37 parents $(91.9 \%)$ investigated the feeding methods in such cases before the birth of their infants. When parents were asked about who provided them with support and help for education in cleft care, they stated that internet, oral and maxillofacial surgeons, pediatricians, other parents with cleft infants, gynaecologist, and orthodontists $(35.6 \%, 28.3 \%$, $16.4 \%, 10.7 \%, 5.3 \%, 3.7 \%$, respectively). Among the 37 parents who knew about their unborn infant cleft condition, $46 \%(n=17)$ confirmed that they had a great feeding education before giving birth and their infants had stayed in the intensive care unit (ICU) for an average 3.7 days in comparison to 7.4 days to the infants that belonged to a parents with no feeding education during pregnancy, but there was no statistically significant difference between two periods with a $\mathrm{p}$ value of 0.05 . Even more, no statistically significant difference regarding rat of admission to the intensive care unit between two groups $(\mathrm{p}=0.05)$. The data received from the questionnaire showed $54 \%(\mathrm{n}=54)$ of the affected infants were admitted to the intensive care unit following birth. Those were divided as follows; 5 cases isolated cleft lip, 15 cases isolated cleft palate, and 34 cases cleft lip and palate. Table 2 contains summery of the responses to the questionnaire.

\section{Breastfeeding}

Only $12.2 \%(\mathrm{n}=11)$ of parents could breastfeed their infants, yet a large percent $77.8(n=79)$ could not. Fifty of those infants had cleft lip and palate, 28 had cleft palate and two had isolated cleft lip. Lowest success rate in breastfeeding come in cleft palate ones despite the presence or absence of cleft lip ( $p<0.001$ ). This study revealed that among the 100 parents 37 used the caregiver service to help in breastfeeding. Ten caregivers were instructed by the intensive care unit physician not to breastfeed. As for the 27 caregivers latching on the breast was reported by 18 caregivers, however, inadequate suction and low flow rate was reported by nine caregivers.

\section{Feeding challenges}

The isolated cleft lip infants showed no feeding difficulties in $86.7 \%$. However, the remaining $13.3 \%$ presented minor issues such as lake of generating proper lip seal, milk regurgitation, postpartum fatigue. Parents reported other faced problems by their infants such as volume intake inadequacy, aspiration, coughing, choking. Patents noticed reduced weight gain and inadequate growth.

\section{Feeding interventions}

Nasogastric or orogastric tube feeding was used for forty percent of the infants, with no percutaneous gastrostomy required for any of the infants (mean, 10.2 days; range, 1 to 74 days). Two infants out of 15 infants (13.3\%) suffered from isolated needed nasogastric tube feeding. The number of infants needed nasogastric tube increased when the palate is involved. Twenty-four cases out 32 suffered from cleft palate only (75\%). As for cases had both cleft lip and palate (66\%) 35 cases out of 53 needed nasogastric tube feeding. Higher ratio of nasogastric feeding was showed in cases affected by both cleft lip and palate ( $\mathrm{p}=0.003$ ). Infants with isolated cleft palate showed a statically significant difference when compered to isolated cleft lip cases regarding nasogastric feeding $(\mathrm{p}<0.05)$. In this study 76 infants were fed with bottles, 53.9\% $(n=41)$ had conventional feeding bottles, 25\% $\quad(n=19)$ 
had the Dr. Brown Bottle (Dr. Brown's, St. Louis, MO, USA), 20.1\% had the Medela Special Needs Feeder, formerly the Haberman bottle (Medela, Inc. Breastfeeding U.S., McHenry, IL, USA). The information collected from caregivers showed 64\% of infants in this study were feed using syringes. Twenty-seven infants (35\%) required palatal obturators out of 77 infants with cleft palate. With high ration of obturators usage $67 \%$ in infants with both cleft lip and palate and less percentage 33\% in isolated cleft palate patients. Twenty-three infants were excluded whom were affected with isolated cleft lip and soft palate affection. The last question in the questioner was about the use of the pacifiers and if it was helpful. Fifty-eight (58\%) parents stated that pacifiers were very helpful. Forty-two infants could not keep the pacifiers in their mouth despite several attempts from the parents.

TABLE (1) Demography of cleft patients

\begin{tabular}{|c|c|c|c|c|}
\hline & $\begin{array}{c}\text { Total } \\
\text { N }(100 \%)\end{array}$ & $\begin{array}{c}\text { Cleft lip } \\
\text { N }(\%)\end{array}$ & $\begin{array}{c}\text { Cleft palate } \\
\text { N }(\%)\end{array}$ & $\begin{array}{c}\text { Cleft lip and palate } \\
\qquad \mathbf{N}(\%)\end{array}$ \\
\hline Total number of infants & 100 & 15 & 32 & 53 \\
\hline \multicolumn{5}{|l|}{ Type of cleft condition } \\
\hline Hard and soft palate & 24 & NA & 24 & NA \\
\hline Soft palate only & 8 & NA & 8 & NA \\
\hline Unilateral & 46 & 14 & NA & 32 \\
\hline Bilateral & 22 & 1 & NA & 21 \\
\hline \multicolumn{5}{|l|}{ Gender } \\
\hline Male & 56 & 10 & 17 & 29 \\
\hline Female & 44 & 5 & 15 & 24 \\
\hline
\end{tabular}

TABLE (2) Simplified summary of the responses to some statements of the questionnaire.

\begin{tabular}{|c|c|c|c|c|}
\hline & & $\begin{array}{c}\text { Total } \\
\text { N }(100 \%)\end{array}$ & $\begin{array}{c}\text { Yes } \\
\mathbf{N}(\%)\end{array}$ & $\begin{array}{c}\text { No } \\
\mathbf{N}(\%)\end{array}$ \\
\hline 1 & Was the cleft lip and /or palate affection diagnosed prenatal via ultrasonography? & 100 & $37(37 \%)$ & $63(63 \%)$ \\
\hline 2 & $\begin{array}{l}\text { During pregnancy and after knowing that your baby is affected by such deformity. } \\
\text { Did you explore and asking how you will feed him? }\end{array}$ & 37 & $34(91.9 \%)$ & $3(8.9 \%)$ \\
\hline 3 & We received an education on different feeding approaches in the prenatal period. & 37 & $17(46 \%)$ & $20(54 \%)$ \\
\hline 4 & My infant was admitted to the intensive care unit immediately after birth. & 100 & $56(56 \%)$ & $44(44 \%)$ \\
\hline 5 & Was your new-born feed via nasogastric or orogastric tube? & 100 & $40(40 \%)$ & $60(60 \%)$ \\
\hline 6 & Could you breastfeed your new-born successfully? (exclusion) & 90 & $11(12.2 \%)$ & $79(77.8 \%)$ \\
\hline 7 & Did you bottle feed your infant? & 100 & $76(76 \%)$ & $34(34 \%)$ \\
\hline 8 & We were instructed to use syringe for feeding. & 100 & $64(64 \%)$ & $36(36 \%)$ \\
\hline 9 & If you used palatal obturator, were it beneficial? Exclusion & 77 & $27(35 \%)$ & $50(65 \%)$ \\
\hline 10 & We used pacifiers and it was very helpful.(exclusion) & 100 & $58(58 \%)$ & $42(42 \%)$ \\
\hline
\end{tabular}




\section{DISCUSSION}

Healthy well-nourished infant is the dream of every parents. Cleft lip and palate as facial deformity impose a shock for parents. Many questions and thoughts roam their minds among which the feeding is one of the most important for ensuring proper development. Growth is crucial as adequate weight gain is a requirement for surgical correction of the deformity. Feeding represent a huge challenge for parents, caregiver and health care team before surgical correction of cleft lip. Most centers perform lip and primary nasal correction at the age of 3 months and palate correction between 6-12 months of age. In this preoperative period to ensure adequate weight gain; feeding intervention is a must because most infants lack the ability to latch to the nipple, suck, maintain proper seal. Success could be achieved via teaching the parents and providing support to face such challenges ${ }^{10,11,12,13}$. In this study the prenatal diagnosis was confirmed in $37 \%$ of the affected cases, that rate was coincide with several previous studies which showed a range from $19 \%$ to $70 \%$ with correspondence to the design of the study ${ }^{14,15,16,17}$.

Feeding difficulties and challenges had been reported by previous studies. Almost all parents are keen to learn ways to fightback these challenges, as reported by many studies, it can reach to $97 \%$ of parents. As for breastfeeding 90\% of mothers demanded demonstration. In a study by Young et al. (2001) reported that $40 \%$ of the parents were not instructed to how to face such feeding difficulties and $55 \%$ were giving a brief information on feeding interventions ${ }^{18,19,20}$. In the present study, out of the 37 infants with prenatal cleft diagnosis, 91.9\%( $n=34)$ parents had investigated the methods that they can feed their infants with, and $46 \%(n=17)$ were educated before the birth of their child. When parents were asked about who provided them with support and help for education in cleft care, they stated that internet, oral and maxillofacial surgeons, pediatricians, other parents with cleft infants, gynaecologist, and orthodontists.

Ten mothers among one-hundred mothers were given order not breastfeed their infants by intensive care physicians. Cleft lip and palate are a multifactorial deformity, in other way, multifactor are sharing the complexity of such deformity. Therefore, a multidisciplinary team for corrective approach and management is the best suite such cases. The team includes social workers, nurses, caretaker and different specialities. The team responsibilities are directed to evaluate the infant's feeding ability, monitor the clinical status of the infant, communication with the parents, hospitalization, alleviate the stress and pressure imposed on the mother ${ }^{21,22}$. In a study by sank et al.2003, revelled that the more support the mother receives the more lessen the maternal depression. O'Brien et al. 2004, suggested a strong link between failure to thrive cleft infant with maternal depression. Severe depression was demonstrated in $35 \%$ of mothers of babies who had an isolated complete cleft palate and were in the deficient weight category ${ }^{23,24}$.

In this study $56 \%$ of infants had been admitted to the intensive care unit, which is more than the percent of parents provided with prenatal diagnosis and of course exceeds the percent of parents received prenatal education. No correlation could be found between the number of admissions to intensive care unit and the number of parents being educated or prepared before birth. A study by Hubbard et al. (2012) reported a correlation between education and (ICU) admission, which the more the number of parents being educated the less the admission ${ }^{25}$. One of the important findings in the present study was the significant correlation between the degree of the cleft lip and palate severity and the need for the nasogastric or orogastric feeding $(\mathrm{p}=0.003)$. Many authors confirmed that if the deformity include cleft palate or isolated cleft palate the more 
the need for nasogastric or orogastric feeding and hospitalization ${ }^{12,26}$. Cleft palate affected feeding far more than cleft lip. Cleft lip affects sealing ability around the nipple and the bottles, yet cleft palate is associated with swallowing, regurgitation and choking, which impose dangerous effect far more than cleft lip and feeding ${ }^{27,28}$.

Only $12.2 \%(n=11)$ of parents could breastfeed their infants, yet a large percent $77.8(\mathrm{n}=79)$ could not. Fifty of those infants had cleft lip and palate, 28 had cleft palate and two had isolated cleft lip. Lowest success rate in breastfeeding come in cleft palate ones despite the presence or absence of cleft lip ( $\mathrm{p}<0.001)$. The isolated cleft lip infants showed no feeding difficulties in $86.7 \%$. However, the remaining $13.3 \%$ presented minor issues such as lake of generating proper lip seal, milk regurgitation, postpartum fatigue which is reliable with other studies. Several studies reported the benefits of using syringe in compassion to spoon in increasing the volume intake and speeding the feeding time to reach the normal 29,30,31. Feeding bottles had proven efficiency in providing infants with the proper quantity they needed for better weight gain. In the present study 76 infants were fed with bottles, 53.9\% ( $\mathrm{n}=41)$ had conventional feeding bottles, 25\% ( $n=19)$ had the Dr. Brown Bottle (Dr. Brown's, St. Louis, MO, USA), 20.1\% had the Medela Special Needs Feeder, formerly the Haberman bottle (Medela, Inc. Breastfeeding U.S., McHenry, IL, USA) and 64\% used syringe for feeding ${ }^{32,33}$.

Massie et al, in 2018 indicated that palatal obturators improved the feeding process for infants affected with isolated cleft palate and infants suffering cleft lip and palate whether unilateral or bilateral. The obturator mechanism is based on closure of the palate defect temporally till the infant finishes his meal. Twenty-seven infants (35\%) required palatal obturators out of 77 infants with cleft palate. With high ration of obturators usage
$67 \%$ in infants with both cleft lip and palate and less percentage $33 \%$ in isolated cleft palate patients. Twenty-three infants were excluded whom were affected with isolated cleft lip and soft palate affection ${ }^{34,35}$. Based on lowe, in 1990 pacifiers increase the sucking efficiency with mandibular stimulation. Fifty-eight (58\%) parents stated that pacifiers were very helpful. Forty-two infants could not keep the pacifiers in their mouth despite several attempts from the parents ${ }^{36,37}$.

\section{CONCLUSION}

This study helped to give clear results to assist caregivers aiding these families. It is very important to diagnose isolated cleft palate. Referral of cleft patients to a professional team. Parent education is helpful in supporting the needs for better feeding of infants affected by cleft. Informe the parents of all feeding interventions

\section{REFERENCES}

1- Choa, R. M., Slator, R., Jeremy, A., Robinson, S., Franklin, D., Roberts, A., ... Clark, V. (2014). Identifying the effect of cleft type, deprivation and ethnicity on speech and dental outcomes in UK cleft patients: A multi-centre study. Journal of Plastic, Reconstructive \& Aesthetic Surgery, 67 , 1637-1643. https://doi.org/10.1016/j.bjps. 2014.07.018.

2- Luijsterburg, A. J., \& Vermeij-Keers, C. (2011). Ten years recording common oral clefts with a new descriptive system. The Cleft Palate-Craniofacial Journal, 48, 173182.https://doi.org/10.1597/08-150.

3- Masarei, A. G., Sell, D., Habel, A., Mars,M., Sommerlad, B. C., \&Wade, A. (2007). The nature of feeding in infants with unrepaired cleft lip and/or palate compared with healthy noncleft infants. The Cleft Palate-Craniofacial Journal, 44, 321-328. https://doi.org/10. 1597/05-185.

4- Masarei, A. G.,Wade, A., Mars, M., Sommerlad, B. C., \& Sell, D. (2007). A randomized control trial investigating the effect of presurgical orthopedics on feeding in infants with cleft lip and/or palate. The Cleft Palate-Craniofacial Journal, 44, 182-193. https://doi. org/10.1597/05-184.1.

5- Kaye A, Cattaneo C, Huff HM, Staggs VS. (2019). A Pilot Study of Mothers' Breastfeeding Experiences in In- 
fants with Cleft Lip and/or Palate. Adv Neonatal Care. 19(2):127-137.

6- Lindberg, N., \& Berglund, A. L. (2014). Mothers' experiences of feeding babies born with cleft lip and palate. Scandinavian Journal of Caring Sciences, 28, 66-73. https://doi.org/10.1111/scs.12048.

7- de Vries, I. A., Breugem, C. C., van der Heul, A.M., Eijkemans, M. J., Kon,M., \&Mink van der Molen, A. B. (2014). Prevalence of feeding disorders in childrenwith cleft palate only: A retrospective study. Clinical Oral Investigations, 18, 1507-1515. https://doi.org/10.1007/s00784-014-1190-9.

8- Reid, J., Kilpatrick, N., \& Reilly, S. (2006). A prospective, longitudinal study of feeding skills in a cohort of babies with cleft conditions. The Cleft Palate-Craniofacial Journal, 43, 702-709. https://doi.org/10.1597/05-172.

9- Kaye,A., Cattaneo, C., Huff, H. M., \& Staggs, V. S. (2018). A pilot study of mothers' breastfeeding experiences in infants with cleft lip and/or palate. Advances in Neonatal Care. https://doi.org/10.1097/ANC.0000000000000551.

10- Gailey, D. G. (2016). Feeding infants with cleft and the postoperative cleft management. Oral and Maxillofacial Surgery Clinics of North America, 28, 153-159. https:// doi.org/10.1016/j.coms.2015.12.003.

11- Kuttenberger J, Ohmer JN and Polska E (2010) Initial counselling for cleft lip and palate: Parents' evaluation, needs and expectations. International Journal of Oral Maxillofacial Surgery 39: 214-220.

12- Britton KFM, McDonald SH and Welbury RR (2011) An investigation into feeding in children born with a cleft lip and/or palate in the West of Scotland. European Academy of Paediatric Dentistry 12(5): 250-255.

13- Kaye AE, Thaete K, Snell A, Chesser C, Goldak C, Huff H. (2017) Initial nutritional assessment of infants with cleft lip and/or palate: interventions and return to birth weight. Cleft Palate Craniofac J.;54(2):127-136.

14- Berggren, H., Hansson, E., Uvemark, A., Svensson, H., Sladkevicius, P., \& Becker, M. (2012). Prenatal ultrasound detection of cleft lip, or cleft palate, or both, in southern Sweden, 2006-2010. Journal of Plastic Surgery and Hand Surgery, 46, 69-74. https://doi.org/10.3109/200065 6X.2012.668773.

15- Demircioglu, M., Kangesu, L., Ismail, A., Lake, E., Hughes, J., Wright, S., \& Sommerlad, B. C. (2008). Increasing accuracy of antenatal ultrasound diagnosis of cleft lip with or without cleft palate, in cases referred to the North Thames London Region. Ultrasound in Obstetrics \& Gynecology, 31, 647-651. https://doi.org/10.1002/ $\operatorname{uog} .5275$.

16- Marginean C, Sasarean V, Marginean CO, Melit LE, Marginean MO. Med Ultrason. (2018). Prenatal diagnosis of cleft lip and cleft lip palate - a case series. 8;20(4):531-535. doi: 10.11152/mu-1582.

17- Abramson Z, Peacock Z, Cohen H, et al. Radiology of cleft lip and palate: imaging for the prenatal period and throughout life. (2015) Radiographics; 35:2053-2063. doi:10.1148/rg.2015150050.

18- Hartzell LD, Kilpatrick LA (2014). Diagnosis and management of patients with clefts: a comprehensive and interdisciplinary approach. Otolaryngol Clin North Am; 47(5):821-52. doi: 10.1016/j.otc.2014.06.010.

19- Lindberg N, Berglund AL (2014). Mothers' experiences of feeding babies born with cleft lip and palate. Scand J Caring Sci; 28(1):66-73. doi: 10.1111/scs.12048.

20- Britton KF, McDonald SH, Welbury RR. (2011). An investigation into infant feeding in children born with a cleft lip and/or palate in the West of Scotland. Eur Arch Paediatr Dent; 12(5):250-5.

21- Young, J. L., O’ Riordan, M., Goldstein, J. A., \& Robin, N. H. (2001). What information do parents of new-borns with cleft lip, palate, or both want to know? The Cleft Palate Craniofacial Journal, 38, 55-58.

22- Martin V1, Greatrex-White S. (2014). An evaluation of factors influencing feeding in babies with a cleft palate with and without a cleft lip. J Child Health Care; 18(1):7283. doi: $10.1177 / 1367493512473853$.

23- Sank JR1, Berk NW, Cooper ME, Marazita ML. (2003). Perceived social support of mothers of children with clefts. Cleft Palate Craniofac J; 40(2):165-71.

24- O’Brien LM, Heycock EG, Hanna M, et al. (2004) Postnatal depression and faltering growth: A community study. Pediatrics 113: 1242-1247.

25- Hubbard, B. A., Baker, C. L., \&Muzaffar, A. R. (2012). Prenatal counseling's effect on rates of neonatal intensive care admission for feeding problems cleft lip/palate infants. Missouri Medicine, 109, 153-156.

26- Baylis AL, Pearson GD, Hall C, Madhoun LL, Cummings C, Neal N, Smith A, Eastman K, Stocker C, Kirschner RE. (2018) A Quality Improvement Initiative to Improve 
Feeding and Growth of Infants with Cleft Lip and/or Palate. Cleft Palate Craniofac J. ;55(9):1218-1224.

27- Ligh, C. A., Fox, J. P., Swanson, J., Yu, J. W., \& Taylor, J. A. (2016). Not all clefts are created equal: Patterns of hospital-based care use among children with cleft lip and palate within 4 years of initial surgery. Plastic and Reconstructive Surgery, 137, 990e-998e.

28- Garcez, L. W., \& Giugliani, E. R. (2005). Population-based study on the practice of breastfeeding in children born with cleft lip and palate. The Cleft Palate-Craniofacial Journal, 42, 687-693.

29- Visser EE, Krüger EE, Margaretha A, Kritzinger AM. (2018). Feeding difficulties in infants with unrepaired cleft lip and palate and HIV-exposure. Afr Health Sci. ; 18(4):1098-1108.

30- Worley ML, Patel KG, Kilpatrick LA. Cleft Lip and Palate. (2018) Clin Perinatol. ;45(4):661-678.

31- Ize-Iyamu, I. N., \& Saheeb, B. D. (2011). Feeding intervention in cleft lip and palate babies: A practical approach to feeding efficiency and weight gain. International Journal of Oral and Maxillofacial Surgery, 40, 916-919.
32- Gottschlich MM, Mayes T, Allgeier C, James L, Khoury J, Pan B, van Aalst JA. (2018). A Retrospective Study Identifying Breast Milk Feeding Disparities in Infants with Cleft Palate. J Acad Nutr Diet.;118(11):2154-2161.

33- Gailey DG. (2016). Feeding Infants with Cleft and the Postoperative Cleft Management. Oral Maxillofac Surg Clin North Am. ;28(2):153-9.

34- Massie JP, Bruckman K, Rifkin WJ, Runyan CM, Shetye PR, Grayson B, Flores RL. (2018). The Effect of Nasoalveolar Molding on Nasal Airway Anatomy: A 9-Year Follow-up of Patients with Unilateral Cleft Lip and Palate. Cleft Palate Craniofac J.;55(4):596-601.

35- Goyal S, Rani S, Pawah S, Sharma P. (2017). A novel approach for prosthodontic management of patient with cleft of palate. J Indian Soc Pedod Prev Dent.;35(3):279-281.

36- Lowe, A. A. (1990). The tongue and airway. Otolaryngologic Clinics of North America, 23, 677-698.

37- da Silva Dalben, G., Costa, B., Gomide, M. R., \& Teixeira das Neves, L. T. (2003). Breastfeeding and sugar intake in babies with cleft lip and palate. The Cleft Palate-Craniofacial Journal, 40, 84-87. 